
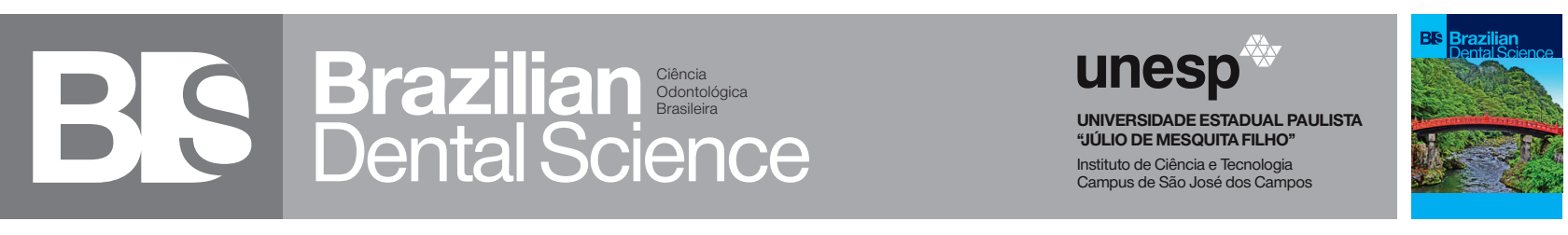

\title{
Bone mineral density and mandibular osteoporotic alterations in type 2 diabetes
}

\author{
Densidade mineral óssea e alterações osteoporóticas na mandíbula em pacientes diabéticos do tipo 2 \\ Luciana MUNHOZ ${ }^{1}$, Isabela Goulart Gil CHOI ${ }^{1}$, Reinaldo ABDALA JÚNIOR ${ }^{1}$, Rogério ABDALA ${ }^{2}$, Emiko Saito ARITA ${ }^{1}$ \\ 1 - Department of Stomatology - School of Dentistry - University of São Paulo - São Paulo - SP - Brazil. \\ 2 - CDB - Centro de Diagnósticos Brasil - Rua Marselhesa, 500 - Vila Mariana, São Paulo - SP - Brazil.
}

\section{ABSTRACT}

Objective: To assess the influence of type 2 diabetes on bone mineral density in a group of type 2 diabetic patients, in comparison with non-diabetic patients. Additionally, to evaluate the correlation between mandibular cortical index and bone mineral density. Material and Methods: 48 patients (24 diabetics and 24 non-diabetics) referred for femur and spine densitometry and panoramic radiograph examination were included in this study. Patients were diagnosed based on densitometric results of the total femur and total spine. All panoramic radiomorphometric measurements were performed by 3 observers. Differences in $\mathrm{T}$ and Z-scores between both groups were evaluated with Mann-Whitney test and non-parametric correlations between mandibular cortical index and T/Z-scores were carried out with Spearman's test. Results: Median T and Z-scores for total femur and total spine presented no statistical significant difference between diabetic and nondiabetic patients. In addition, only diabetics total femur and non-diabetics total spine T-scores were significantly correlated with mandibular cortical index. Conclusion: The present results suggest that type 2 diabetic patients have similar $\mathrm{Z}$ and $\mathrm{T}$-scores in femur and spine when compared to non-diabetic patients. Mandibular cortical index, assessed on panoramic radiographs is inversely correlated with femur densitometry results in diabetics and spine bone mineral density in nondiabetic patients.

\section{KEYWORDS}

Bone Mineral Density; Dual X-Ray Absorptiometry; Panoramic radiography; Osteoporosis; Type 2 Diabetes.

\section{RESUMO}

Objetivo: avaliar a influência do diabetes tipo 2 na densidade mineral óssea em um grupo de pacientes diabéticos do tipo 2 , em comparação com pacientes não diabéticos. Adicionalmente, analisar a correlação entre o índice cortical mandibular e a densidade mineral óssea. Material e Métodos: 48 pacientes (24 diabéticos e 24 não diabéticos) que realizaram densitometria óssea de fêmur e coluna vertebral e exame radiográfico panorâmico foram incluídos neste estudo. Os pacientes foram diagnosticados com base nos resultados densitométricos do fêmur total e da coluna total. Por meio das radiografias panorâmicas, 3 observadores avaliaram o índice da cortical mandibular. Diferenças em $\mathrm{T}$ e Z scores entre os dois grupos foram avaliadas com o teste de MannWhitney e as correlações não paramétricas entre o índice cortical mandibular e os scores da densitometria foram verificadas por meio do teste de Spearman. Resultados: A mediana dos T e Z-scores para fêmur total e coluna total não apresentaram diferença estatisticamente significante entre diabéticos e não-diabéticos. Além disso, houve correlação significativa com o índice da cortical mandibular somente os T-scores de fêmur total do grupo de pacientes diabéticos e de coluna total dos paciente não-diabéticos. Conclusão: Os resultados deste estudo sugerem que pacientes diabéticos tipo 2 tem densidade mineral óssea aferida por meio de densitometria óssea do fêmur e coluna total semelhantes aos não-diabéticos. $\mathrm{O}$ índice cortical mandibular, avaliado em radiografias panorâmicas, foi inversamente correlacionado com os resultados da densitometria do fêmur em pacientes diabéticos e da densitometria de coluna total de pacientes não diabéticos.

\section{PALAVRAS-CHAVE}

Densidade mineral óssea; Radiografia panorâmica; Osteoporose; Diabetes do tipo 2; Densitometria óssea. 


\section{INTRODUCTION}

$\mathrm{O}$ steoporosis is a metabolic disease which affects bone mineral density (BMD) leading to increased low-energy fracture risk [1]. Type 1 and type 2 diabetes are recognized as potential modifier diseases to BMD and osteoporotic fracture risk [2]. However, the osteoporosis risk among diabetic patients remains unclear.

In type 1 diabetes, the full insulin deficiency and the osteoblast deficit are associated with the reduced BMD [3]. However, in type 2 diabetes, the disease physiopathology is unclear [4] and the consensus on osteoporosis risk in diabetic patients has not been reached. Studies considering BMD in diabetic patients provide distinct results [5]: some studies verified increase $[6,7]$ in BMD but others decreased [8] or BMD no difference between type 2 diabetics and non-diabetic patients [9]. It is uncertain whether the usually named as "diabetic osteopathy" disease actually affects diabetic patients [10].

The gold-standard examination to detect BMD alterations is dual x-ray absorptiometry (DXA), which allows high precision BMD measurement using minimal radiation. However, DXA is not broadly accessible in many countries [11]. Notwithstanding, it is possible to investigate osteoporotic alterations in mandibular cortical bone by using radiomorphometric indexes on panoramic radiographs [12], frequently requested in clinical dentistry practice mainly in oral and maxillofacial area. Unlike DXA, panoramic radiograph is a lowcost and easily accessible examination.

One of the most studied radiomorphometric index is the "Mandibular Cortical Index" (MCI) which was developed to assess the endosteal margin of the mandibular cortex [13]. It is a qualitative analysis, and the endosteal margin is classified as C1, C2 or C3 according to the apparent intracortical bone erosion pattern presented. MCI is supported to be effective in screening patients at low BMD risk, and it is inversely correlated with BMD in many distinct populations $[1,7,13]$ as well as in diabetic patients [7].

Thus, this study objective is to assess the influence of type 2 diabetes on total femoral and total spine BMD in a group of type 2 diabetes patients, in comparison with nondiabetic patients. Additionally, we also evaluate the correlation between MCI and BMD from femoral and spine skeleton sites.

\section{MATERIALS AND METHODS}

\section{exclusion criteria}

All patients willing to participate in this study signed an informed consent form. The guidelines of Helsinki were followed in this investigation. Approval was obtained from university's ethics committee (number FR358902).

This retrospective study was initially conducted with 64 patients, referred to dental treatment at the University dental clinic (São Paulo, São Paulo State, Brazil) who had undergone panoramic radiographic examination and femoral and spine DXA (at a private medical imaging clinic in the same city) between 2010 and 2014. From this initial sample, 9 patients who did not undergo panoramic radiographic examination and DXA on the same day or who had no technically acceptable radiographs were excluded.

Presence of other metabolic bone diseases (such as thyroid diseases), or history of medication intake affecting bone metabolism (such as glucocorticoids or bisphosphonate) were considered as exclusion criteria. Considering the aforementioned, 7 patients were excluded.

The final sample included 48 patients. Then, patients were classified as either diabetics or non-diabetics, according to clinical history file and confirmed with blood examinations, which included glycated hemoglobin measurements. A flow chart detailing the inclusion and exclusion criteria is available on Figure 1. 


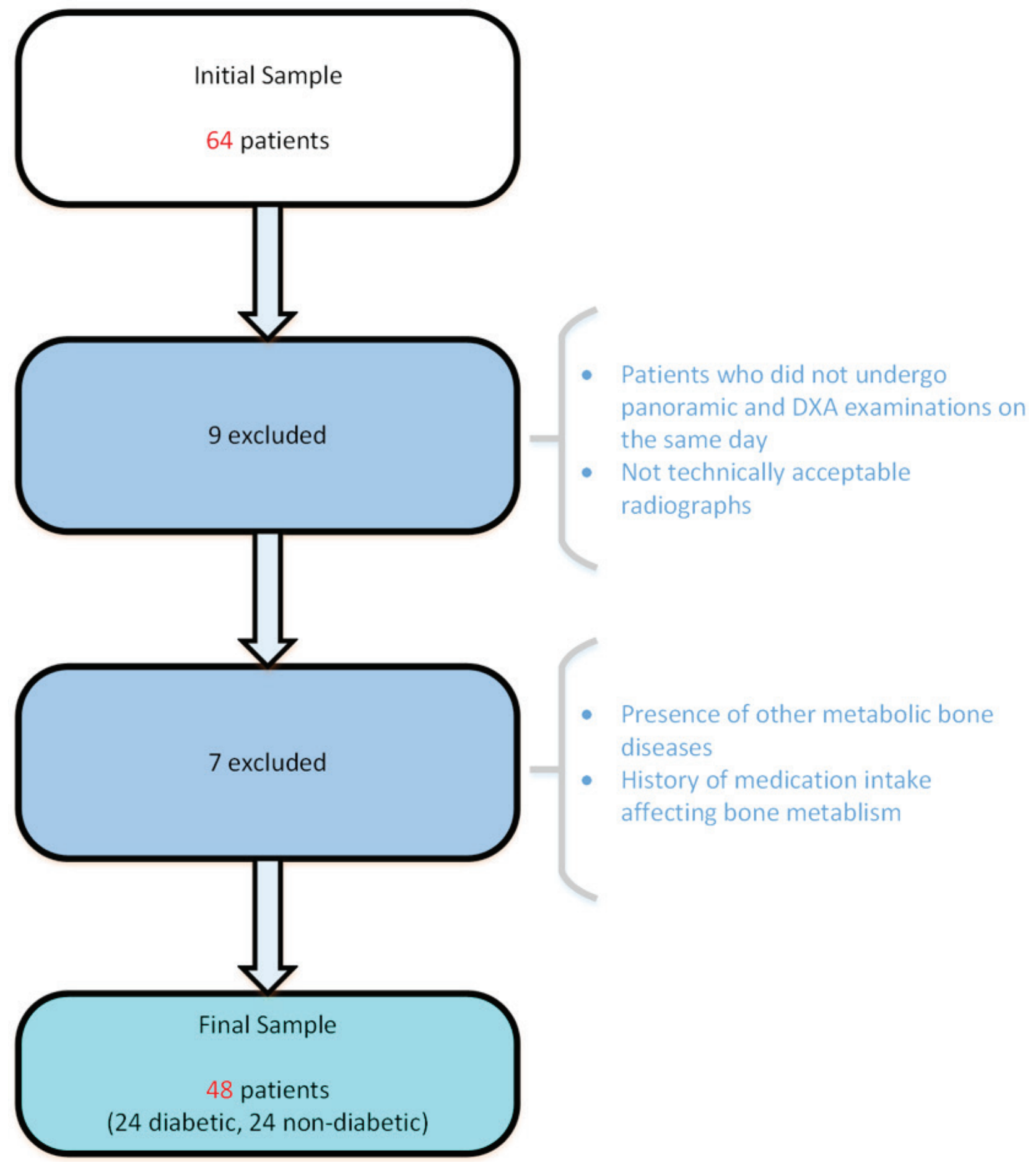

Figure 1 - Flow chart demonstrating inclusion and exclusion criteria. 


\section{Dual x-ray absorptiometry}

Bone densitometry measurements were carried out with central dual energy X-ray absorptiometry (Hologic Discovery DXA system, Hologic Inc, Marlborough, MA, USA). The region of choice for scanning was the femur and spine. Patients were diagnosed based on BMD values of the total femur and total spine, measured according to World Health Organization (WHO) criteria, as normal ( $\mathrm{T}$ score $>-1.0$ ), osteopenic (T score, -1.0 to -2.5 ) and osteoporotic (T-score $\leq-2.5$ SD) [14]. Moreover, Z-score values were also recorded and used to classify the patients as either normal ( $\mathrm{Z}$ score $>2$ ) or with low bone density ( $Z$ score $<2$ ).

\section{Panoramic radiographs}

All digital panoramic radiography images were taken using the same device (Kodak 8000 Digital Panoramic, Eastman Kodak Company, USA). All images were processed on the same software (ImageJ, National Institute of Health, Bethesda, MD, USA).

\section{Mandibular Cortical Index (MCI)}

The MCI was analysed by evaluating the appearance of the endosteal margin at the cortical bone below the mandibular foramen, using Klemetti classification [13]. The inferior mandibular cortex was classified as: $\mathrm{C} 1=$ normal, when presenting an even and sharp endosteal margin; C2 = moderately eroded, when presenting evidence of lacunar/linear resorption or endosteal cortical residues; and C3 = severely eroded, when porosity was markedly observed. All panoramic radiomorphometric measurements were performed in random order by three trained observers (i.e. dentists having expertise in oral radiology and previous experience with MCI classification). An example of MCI classification is available on Figure 2.

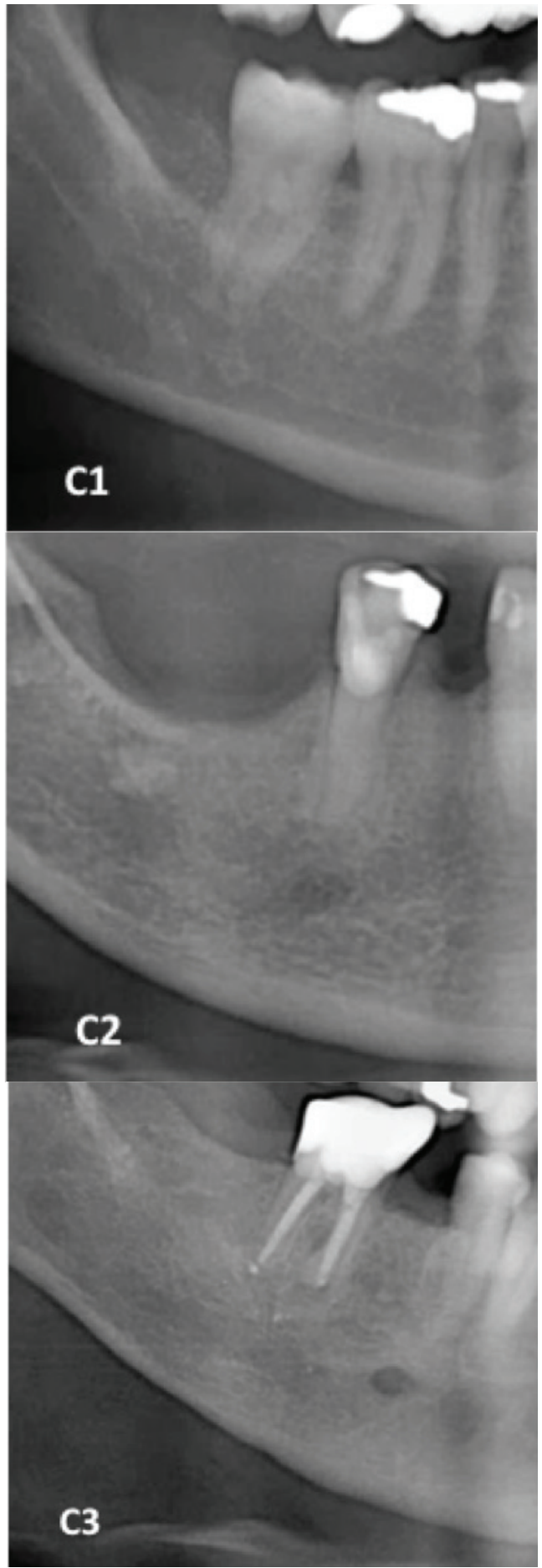

Figure 2 - Mandibular cortical index example: C1, C2 and C3 classifications. 


\section{Statistical Analysis}

Intraobserver reliability was assessed between measurements performed 2 weeks apart to eliminate memory bias. Intra and interobserver agreement were assessed using the kappa test for MCI.

Normality was assessed for continuous variables using the Shapiro-Wilk test. Differences in T- and Z-scores between type 2 diabetic and non-diabetic patients were evaluated with the Mann-Whitney test. In addition, non-parametric correlations between MCI and T- and Z-scores were carried out with Spearman's test.

All statistical analyses were performed at a level of significance of 5\%, using IBM SPSS Statistics 17, SPSS ${ }^{\circ}$, Inc, Chicago, IL.

\section{RESULTS}

A total of 48 patients was analysed, 24 nondiabetic and 24 diabetics (21 diabetic women; 21 non-diabetic women; 3 diabetic men and 3 nondiabetic men). None of the diabetic patients were insulin-dependent. Normality wasn't confirmed for MCI, T- and Z-scores, according to the ShapiroWilk test $(\mathrm{p}<0.05)$. Patients demographic data was described as median and interquartile range (IR) in Table 1.
Intraobserver reproducibility (kappa $=0.82$, 95\% CI $=0.76-0.89, \mathrm{p}<0.05)$ and interobserver reliability were confirmed for MCI categorical measurements $\quad(k a p p a=0.80, \quad 95 \% \quad \mathrm{CI}=0.74$ 0.87, $\mathrm{p}<0.05)$.

Median T-score values for total femur and total spine presented no statistically significant difference between diabetics and non-diabetics patients $(p=0.498$ and $p=0.642$ respectively, according to Mann-Whitney test), as presented in Figure 3.

Median Z-score values for total femur and total spine also presented no statistically significant difference between the two groups $(\mathrm{p}=0.844$ and $\mathrm{p}=0.842$ respectively, according to Mann-Whitney test). Figure 4 demonstrates Median Z-scores for total femur and spine in diabetics and non-diabetics patients.

In addition, only diabetic patient total femur T-score values was significantly correlated with MCI ( $\mathrm{r}=-0.554, \mathrm{p}=0.05)$ and non-diabetic total spine T-score values was significantly correlated with MCI. Non-parametric correlations results are available on Table 2. The two significant correlations found were also illustrated in Figures 5 and 6 (dispersion graphs considering T-scores and MCI).

Table 1 - Demographic data of the study. Number of participants, median age, bone mineral density, mandibular cortical index, total femur $T$ and $Z$-scores, total spine $T$ and $Z$ scores

\begin{tabular}{|c|c|c|c|c|c|c|c|c|}
\hline Group & $\begin{array}{l}\text { Number of } \\
\text { participants }\end{array}$ & Age (years) & BMI & MCI & $\begin{array}{l}\text { Total Femur } \\
\text { T-score }\end{array}$ & $\begin{array}{c}\text { Total Spine } \\
\text { T-score }\end{array}$ & $\begin{array}{l}\text { Total Femur } \\
\text { Z-score }\end{array}$ & $\begin{array}{c}\text { Total Spine } \\
\text { Z-score }\end{array}$ \\
\hline Diabetics & 24 & 67.00 (IR9.75) & 29.27 (IR6.30) & $2(\mid \mathrm{R} 1)$ & $-1.0($ IR1.48) & -1.3 (IR2.13) & $0.2(\mathrm{IR} 1.18)$ & 0.0 (IR1.55) \\
\hline Non-diabetics & 24 & 69.50 (IR14.00) & 27.65 (IR4.19) & $2(\mathrm{IR} 2)$ & $-1.0($ IR1.85) & -1.5 (IR1.68) & 0.35 (IR1.58) & 0.30 (IR1.18) \\
\hline
\end{tabular}

Abbreviations: BMI: Bone Mass Index; MCl: Mandibular Cortical Index; IR: Interquartile Range.

Table 2 - Non-parametric correlations: MCl vs total femur and spine T/Z-scores of the participants, according to Spearman's test

\begin{tabular}{ccccc}
\hline Group & Femur T-score & Spine T-score & Femur Z-score & Spine Z-score \\
Diabetics & $r=-0.554$ & $r=-0.130$ & $r=-0.330$ & $r=0.81$ \\
& $p<0.001$ & $p=0.546$ & $p=0.115$ & $p=0.707$ \\
Non-diabetics & $r=-0.179$ & $r=-0.407$ & $r=0.253$ & $r=-0.011$ \\
& $p=0.403$ & $p=0.049$ & $p=0.233$ & $p=0.961$
\end{tabular}

${ }^{*}$ According to Spearman test, significant if $p<0.05$. 


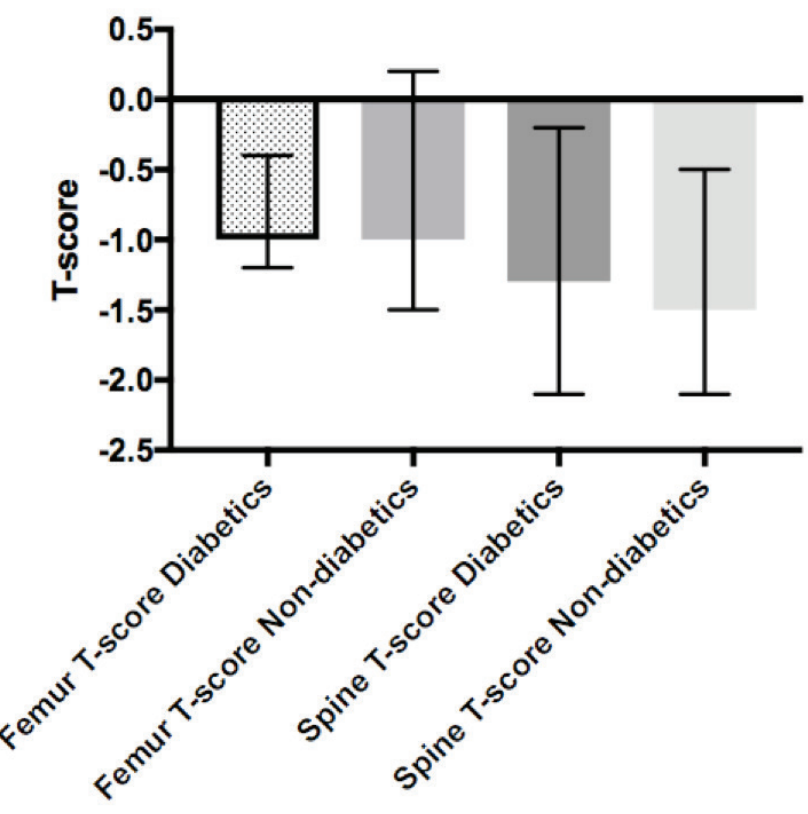

Figure 3 - Median T-score values: Total Femur and Total Spine in Diabetics and Non-diabetics.

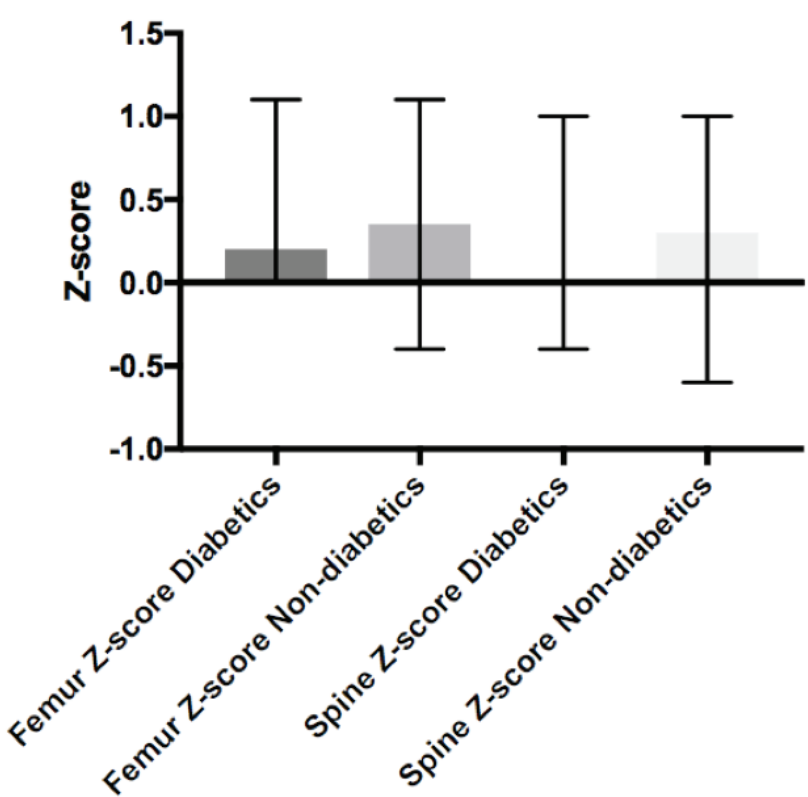

Figure 4 - Median Z-score values: Total Femur and Total Spine in Diabetics and Non-diabetics.

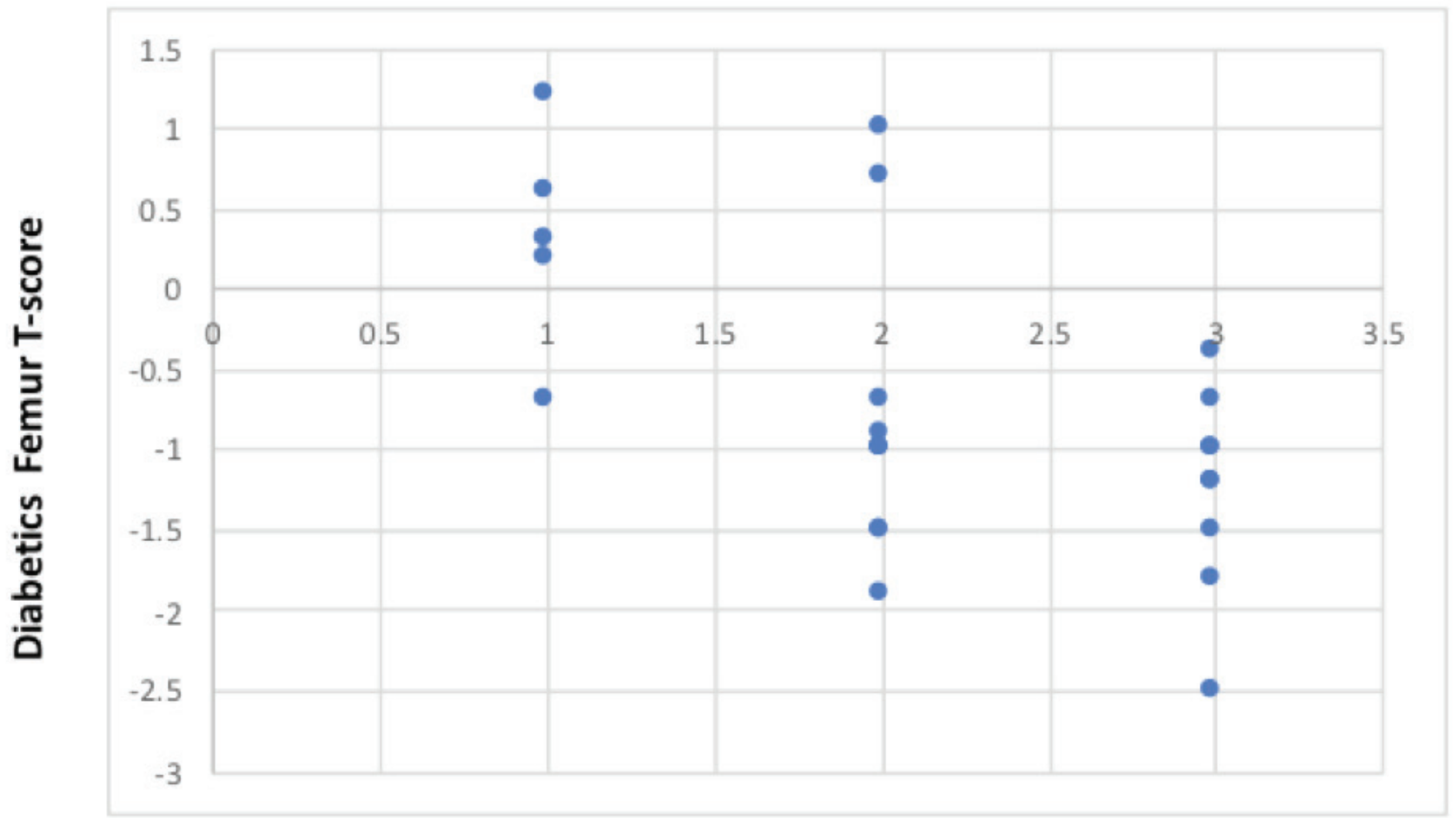

\section{Mandibular Cortical Index}

Figure 5 - Dispersion diagram representing the significant correlation found to Femoral T-scores in diabetic patients and MCl. 


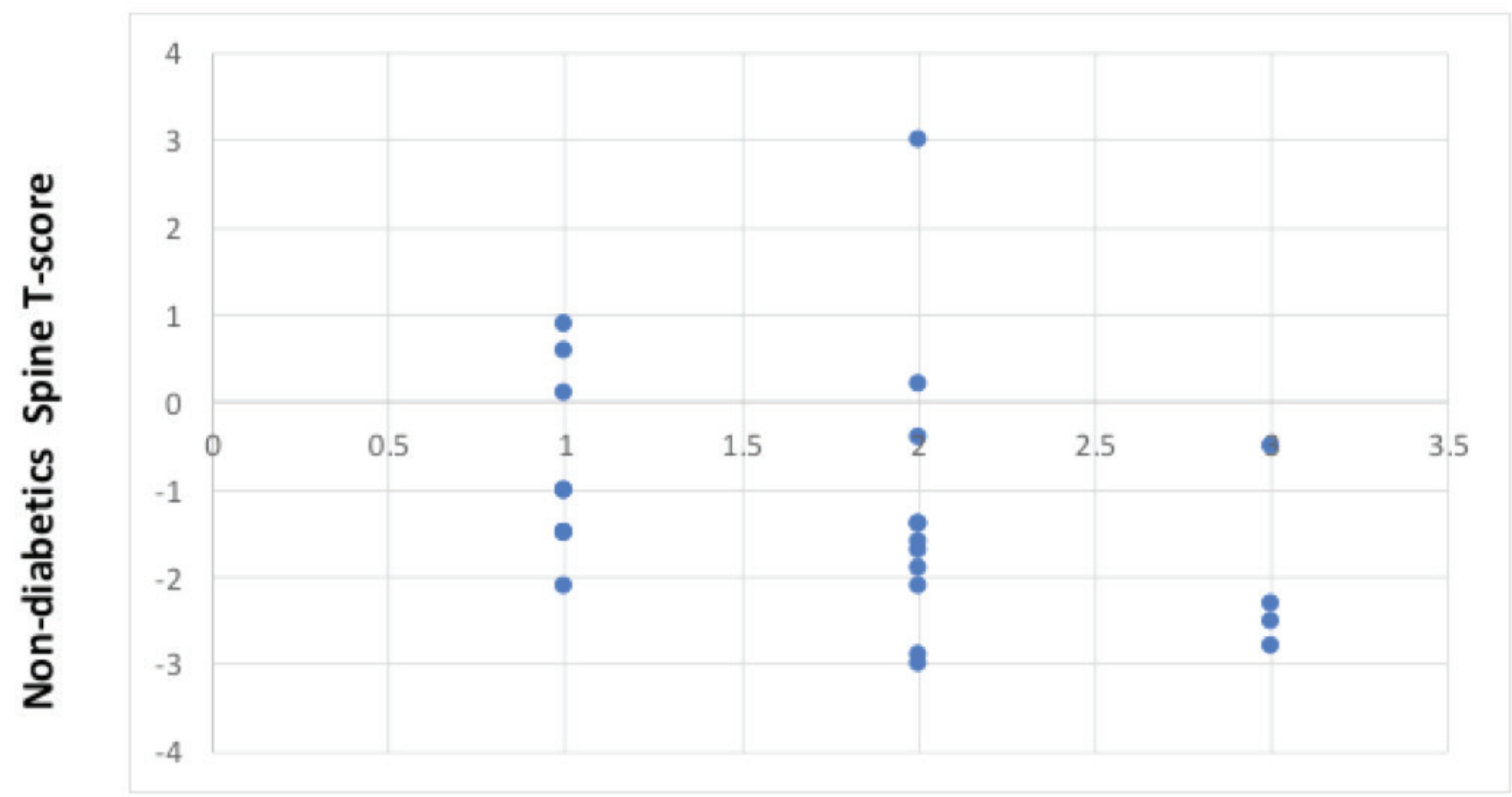

\section{Mandibular Cortical Index}

Figure 6 - Dispersion diagram representing the significant correlation found to Non-diabetic patients Spine T-scores and MCl.

\section{DISCUSSION}

In this study, we found no statistically significant differences between type 2 diabetic and non-diabetic patients in $\mathrm{Z}$ and $\mathrm{T}$-scores at total femur and spine. Additionally, we have found an inverse correlation between total femur T-scores and MCI in diabetic patients. In nondiabetic patients, MCI was inversely correlated with spine T-scores.

The importance of assessing mandibular bone density, despite of the method applied, is appropriate prior to dental procedures such as treatment of periodontal diseases, osseointegrated implants or grafting [15], avoiding unsuitable post-procedures outcomes.

As aforementioned, there is an inconsistence about how type 2 diabetes influences BMD, due to the lack of information about the precise disease physiopathological mechanisms [15]. The disease usual feature is the altered glucose tolerance or impaired lipid associated to carbohydrate metabolism [15]. However, diabetes and osteoporosis are usually simultaneous conditions [16] and osteoporotic fractures are indeed more frequent in diabetic patients [5]. In type 2 diabetic patients, as previously observed, BMD might be increased $[7,17,18]$ or even decreased $[19,20]$ when compared to non-diabetics. In this study, type 2 diabetic patients showed a similar $\mathrm{Z}$ and T-score to non-diabetics, which is in agreement with preceding researches [21,22]. When considering only mandibular BMD measured by an appropriate DXA equipment, previous research found no statistically significant difference in BMD between diabetics and non-diabetics patients [15].

Possible reasons for this disagreement may not be related to osteoporosis itself, but other complications inherent to the diabetic condition, such as impaired eyesight, cerebral ischemia or inefficient balance resulting from neuropathy [16]. Furthermore, microvascular alterations may lead to reduced blood flow to the bones [16] and consequently affect bone remodeling. 
Likewise, osteoporosis affects jawbones and results in visible modification in dental panoramic radiographs, these detectable modifications might potentially speed up periodontal bone resorption caused by periodontal disease [23]. Additionally, diabetes can also affect periodontal inflammatory diseases and, consequently, marginal bone loss. Periodontal diseases are worse among poorly controlled diabetic patients when compared to well-controlled diabetic patients or even nondiabetic individuals [24], essentially alveolar bone loss associated to periodontitis [25]. However, in diabetic patients with a good metabolic control, the degree of alveolar bone loss is similar than non-diabetic patients[26]; nevertheless, a peculiar result was found in another study which considered diabetes medication intake, and concluded that non-insulin dependent diabetic patients can have a more severe progression of alveolar bone loss when compared to health patients [27].

Notwithstanding, part of the divergence between results on the effects of type 2 diabetes on BMD may be as a consequence of heterogeneous study groups available in literature $[9,15,28,29]$. In this study, diabetic and non-diabetic groups were matched according to age, sex and body mass index (BMI).

Type 2 diabetes is routinely associated with overweight $[30,31]$ and higher BMI is positively associated with BMD [32]. Nevertheless, overweight may beless protective against fractures than previously estimated $[33,34]$ and recently it has been demonstrated that higher BMI did not modify BMD loss [2]. Ageing is also considered as an influencing factor for osteoporosis [35]: as the population ages, the number of individuals affected by the osteoporosis rises as well. We selected the matching non-diabetic group taking into account these arguments.

Albeit BMD is primarily measured by DXA, other imaging examinations, such as panoramic radiographs, have also been described as potential and reliable screening tools to screen patients at risk of low BMD [13]. As an additional objective of this study, we evaluated the correlation between MCI and DXA results. To our knowledge, this is the second study which correlates MCI with BMD in diabetic patients [7], but the first in identifying this correlation using total femur T-score results. Nonetheless, we have not found this correlation with total spine for diabetics and total femur for non-diabetic patients. The small sample size may be the reason for this lack of correlation. MCI has already been described as inversely correlated with BMD in other populations [1,13]. These results reinforce the affirmation that skeletal BMD reduction leads to alterations in mandibular BMD and shape [36,37], which can be detected by MCI.

The limitations of the present investigation are the small sample size and the retrospective design. Also, the lack of information about dietary conditions, time of diabetes diagnosis and glycated hemoglobin range. Larger population-based prospective investigations are recommended to verify the influence of type 2 diabetes on BMD, as well as to evaluate the correlation between MCI in distinct DXA skeleton sites.

\section{CONCLUSION}

In conclusion, the present results suggest that type 2 diabetic patients have similar $\mathrm{Z}$ and $\mathrm{T}$-scores in total femur and spine when compared to non-diabetic patients. MCI, assessed on panoramic radiographs is inversely correlated with total femur DXA results in diabetic patients and spine in non-diabetic patients.

\section{ACKNOWLEDGMENTS}

We'd like to thank the CDB - Centro de Diagnósticos Brasil for providing us with the scientific material required to perform this study. 


\section{REFERENCES}

1. Kim OS, Shin MH, Song IH, Lim IG, Yoon SJ, Kim OJ, et al. Digital panoramic radiographs are useful for diagnosis of osteoporosis in Korean postmenopausal women. Gerodontology.2016 Jun;33(2):185-92.

2. Leslie WD, Morin SN, Majumdar SR, Lix LM. Effects of obesity and diabetes on rate of bone density loss. Osteoporos Int. 2017 Jan;29(1):61-7.

3. Leidig-Bruckner G, GrobholzS, Bruckner T, Scheidt-Nave C,NawrothP, Schneider JG. Prevalence and determinants of osteoporosis in patients with type 1and type 2 diabetes mellitus. BMC Endocr Disord. 2014 Apr 11;14:33. doi: 10.1186/1472-6823-14-33.

4. Abdulameer SA, Sulaiman SA, Hassali MA, Subramaniam K, Sahib MN. Osteoporosis and type 2 diabetes mellitus: what do we know, and what we can do? Patient Prefer Adherence. 2012;6:435-48. doi: 10.2147/PPA.S32745.

5. Vestergaard P.Discrepancies in bone mineral density and fracture risk in patients with type 1 and type 2 diabetes--a meta-analysis. Osteoporos Int. 2007 Apr;18(4):427-44.

6. Melton LJ, Riggs BL, Leibson CL, Achenbach SJ, Camp JJ, Bouxsein ML, etal. A bone structural basis for fracture risk in diabetes. J Clin Endocrinol Metab. 2008 Dec;93(12):4804-9.

7. MunhozL, Cortes AR, AritaES. Assessment of osteoporotic alterations in type 2 diabetes: a retrospective study.Dentomaxillofac Radiol. 2017 Aug;46(6):20160414.

8. Bauer DC, Browner WS, Cauley JA, Orwoll ES, Scott JC, Black DM, etal. Factors associated with appendicular bone mass in older women. The Study of Osteoporotic Fractures Research Group. Ann Intern Med. 1993 May;118(9):65765.

9. Tuominen JT, Impivaara 0, PuukkaP, Rönnemaa T. Bone mineral density in patients with type 1and type 2 diabetes. Diabetes Care. 1999 Jul;22(7):1196200.

10. Leidig-Bruckner G,Ziegler R. Diabetes mellitus a risk for osteoporosis? Exp Clin Endocrinol Diabetes. 2001;109 Suppl2:S493-514.

11. Taguchi A, Tsuda M, Ohtsuka M, Kodamal,Sanada M, Nakamoto T, et al. Use of dental panoramic radiographs in identifying younger postmenopausal women with osteoporosis. Osteoporos Int.2006 Dec;17(3):387-94.

12. VerheijJG, Geraets WG, van der SteltPF, Horner K, Lindh C, NicopoulouKarayianni K, etal. Prediction of osteoporosis with dental radiographs and age. Dentomaxillofac Radiol. 2009 May;38(7):431-7.

13. Klemetti E, Kolmakov S, Kröger H. Pantomography in assessment of the osteoporosis risk group. Scand J Dent Res. 1994 Feb;102(1):68-72.

14. Assessment of fracture risk and its application to screening for postmenopausal osteoporosis. Report of a WHO Study Group. World Health Organ Tech Rep Ser. 1994;843:1-129.

15. Ay S, Gursoy UK, Erselcan T, Marakoglu I. Assessment of mandibular bone mineral density in patients with type 2 diabetes mellitus. Dentomaxillofac Radiol.2005 Nov;34(6):327-31.

16. Starup-Linde J, Vestergaard P.Management of endocrine disease: Diabetes and osteoporosis: cause for concern? Eur J Endocrinol. 2015 Sep;173(3):R93-9.

17. Schwartz AV, VittinghoffE, Bauer DC, Hillier TA, Strotmeyer ES, Ensrud KE, etal. Association of BMD and FRAX score with risk of fracture in older adults with type 2 diabetes. JAMA. 2011 Jun;305(21):2184-92.

18. Mathen PG, Thabah MM,Zachariah B,Das AK. Decreased Bone Mineral Density at the Femoral Neck and Lumbar Spine in South Indian Patients with Type2 Diabetes. JClin Diagn Res. 2015 Sep;9(9):0C08-12.
19. Majima T, Komatsu Y,Yamada T, Koike Y,Shigemoto M, Takagi C, etal. Decreased bone mineral density at the distal radius, but not at the lumbar spine or the femoral neck, in Japanese type 2 diabetic patients. Osteoporos Int. 2005 Aug;16(8):907-13.

20. Dutta M, Pakhetra R, Garg M. Evaluation of bone mineral density in type 2 diabetes mellitus patients before and after treatment. Med J Armed Forces India. 2012;68(1):48-52.

21. Anaforoglu I,Nar-Demirer A, Bascil-Tutuncu N, Ertorer ME. Prevalence of osteoporosis and factors affecting bone mineral density among postmenopausal Turkish women with type 2 diabetes. J Diabetes Complications. 2009 Jan-Fev;23(1):12-7.

22. Agius R, Galea R, Fava S. Bone mineral density and intervertebral disc height in type 2 diabetes. J Diabetes Complications. 2016 May-Jun;30(4):644-50.

23. von Wowern N, Kollerup G. Symptomatic osteoporosis: a risk factor for residual ridge reduction of the jaws. JProsthet Dent. 1992 May;67(5):656-60.

24. Javed F, Thafeed Alghamdi AS, Mikami T,Mehmood A, Ahmed HB, Samaranayake LP, etal. Effect of glycemic control on self-perceived oral health, periodontal parameters, and alveolar bone loss among patients with prediabetes. J Periodontol. 2014 Fev;85(2):234-41.

25. Marugame T, Hayasaki H, Lee K, Eguchi H, Matsumoto S. Alveolar bone loss associated with glucose tolerance in Japanese men. Diabet Med. 2003 Sep;20(9):746-51.

26. Tervonen T, Karjalainen K, Knuuttila M, Huumonen S. Alveolar bone loss in type 1 diabetic subjects. J Clin Periodontol. 2000 Aug;27(8):567-71.

27. Taylor GW, BurtBA, Becker MP, Genco RJ, Shlossman M, Knowler WC, etal Non-insulin dependent diabetes mellitus and alveolar bone loss progression over 2 years. J Periodontol. 1998 Jan;69(1):76-83.

28. Rianon N, Ambrose CG, Buni M, WattG, Reyes-OrtizC, Lee M, etal. Trabecular Bone Score Is a Valuable Addition to Bone Mineral Density for Bone Quality Assessment in Older Mexican American Women With Type 2 Diabetes. JClin Densitom. 2018 Mar 27.pii: S1094-6950(17)30255-X. doi:10.1016/j. jocd.2018.02.004.

29. MunhozL, Cortes AR, AritaES. Assessment of osteoporotic alterations in type 2 diabetes: a retrospective study. Dentomaxillofac Radiol. 2017 Aug:46(6):20160414.

30. van Daele PLA. Bone Density in Non-Insulin-Dependent Diabetes Mellitus: The Rotterdam Study. Ann Intern Med. 1995 Mar 15;122(6):409-14.

31. Walsh JS, Vilaca T. Obesity, Type 2 Diabetes and Bone in Adults. Calcif Tissue Int. 2017 May;100(5):528-35.

32. Yang S, Shen X. Association and relative importance of multiple obesity measures with bone mineral density: the National Health and Nutrition Examination Survey 2005-2006. Arch 0steoporos. 2015;10:14. doi:10.1007/ s11657-015-0219-2.

33. Compston JE, Watts NB, Chapurlat R, Cooper C, Boonen S, Greenspan S, etal. Obesity is not protective against fracture in postmenopausal women: GLOW. Am J Med. 2011 Nov;124(11):1043-50.

34. Prieto-Alhambra D, Premaor MO, Fina AvilésF, HermosillaE, Martinez-Laguna $\mathrm{D}$, Carbonell-AbellaC, et al. The association between fracture and obesity is site-dependent: a population-based study in postmenopausal women. J Bone Miner Res. 2012 Fev;27(2):294-300.

35. Albrand G,MunozF, Sornay-Rendu E, DuBoeuf F,Delmas PD. Independent predictors of all osteoporosis-related fractures in healthy postmenopausal women: the OFELY study. Bone. 2003 Mar;32(1):78-85. 
36. Dutra V,Devlin H, Susin C, Yang J, Horner K, Fernandes AR. Mandibular morphological changes in low bone mass edentulous females: evaluation of panoramic radiographs. Oral Surg Oral Med Oral Pathol Oral Radiol Endod. 2006 Nov;102(5):663-8.
37. Taguchi A, Suei Y, Sanada M, Ohtsuka M, Nakamoto T, Sumida H, etal Validation of dental panoramic radiography measures for identifying postmenopausal women with spinal osteoporosis. AJR Am J Roentgenol 2004Dec;183(6):1755-60.

\section{Luciana Munhoz}

(Corresponding address)

Department of Stomatology, School of Dentistry, University of São Paulo.

2227 Lineu Prestes Avenue. Zip code: 05508-000. São Paulo, SP, Brazil.

Telephone and fax number: +55 11 3091-7831.

E-mail address: dra.lucimunhoz@usp.br 